\title{
Olive Leaf Extract Attenuates Obesity in High-Fat Diet-Fed Mice by Modulating the Expression of Molecules Involved in Adipogenesis and Thermogenesis
}

\author{
Ying Shen, Su Jin Song, Narae Keum, and Taesun Park \\ Department of Food and Nutrition, Brain Korea 21 PLUS Project, Yonsei University, 50 Yonsei-ro, Seodaemun-gu, \\ Seoul 120-749, Republic of Korea \\ Correspondence should be addressed to Taesun Park; tspark@yonsei.ac.kr
}

Received 2 October 2013; Revised 12 December 2013; Accepted 17 December 2013; Published 28 January 2014

Academic Editor: Yoshiyuki Kimura

Copyright (C) 2014 Ying Shen et al. This is an open access article distributed under the Creative Commons Attribution License, which permits unrestricted use, distribution, and reproduction in any medium, provided the original work is properly cited.

\begin{abstract}
The present study aimed to investigate whether olive leaf extract (OLE) prevents high-fat diet (HFD)-induced obesity in mice and to explore the underlying mechanisms. Mice were randomly divided into groups that received a chow diet (CD), HFD, or $0.15 \%$ OLE-supplemented diet (OLD) for 8 weeks. OLD-fed mice showed significantly reduced body weight gain, visceral fat-pad weights, and plasma lipid levels as compared with HFD-fed mice. OLE significantly reversed the HFD-induced upregulation of WNT10band galanin-mediated signaling molecules and key adipogenic genes (PPAR $\gamma, \mathrm{C} / \mathrm{EBP} \alpha, \mathrm{CD} 36$, FAS, and leptin) in the epididymal adipose tissue of HFD-fed mice. Furthermore, the HFD-induced downregulation of thermogenic genes involved in uncoupled respiration (SIRT1, PGC1 $\alpha$, and UCP1) and mitochondrial biogenesis (TFAM, NRF-1, and COX2) was also significantly reversed by OLE. These results suggest that OLE exerts beneficial effects against obesity by regulating the expression of genes involved in adipogenesis and thermogenesis in the visceral adipose tissue of HFD-fed mice.
\end{abstract}

\section{Introduction}

Obesity is an energy balance disorder in which energy intake exceeds energy expenditure, resulting in excessive accumulation of white adipose tissue (WAT) [1]. Adipogenesis is the process by which the mesenchymal precursor cells differentiate into adipocytes [2]. Research over the past decade has established the Wnt/ $\beta$-catenin signaling pathway as an important regulator of adipogenesis [3]. WNT10b expression inhibits adipogenesis by suppressing the expression of transcription factors, proliferator-activated receptor gamma $(\operatorname{PPAR} \gamma)$, and CCAAT/enhancer-binding protein alpha $(\mathrm{C} / \mathrm{EBP} \alpha)[4]$, thereby inhibiting WAT development in vivo. Galanin has also been reported to play an essential role in regulating adipogenesis in animal models [5]. HFDinduced adipogenesis in the visceral adipose tissue of mice can be activated through the expression of galanin and its receptors together with the expression of the downstream molecules such as Ras, c-Raf, protein kinase C delta $(\mathrm{PKC} \delta$ ), and extracellular signal-regulated kinases (ERKs) that stimulate the activation of PPAR $\gamma$ and $\mathrm{C} / \mathrm{EBP} \alpha$ [5]. Thus, therapeutic agents that increase WNT10b expression and decrease galanin expression may suppress the expression of adipogenic molecules, thereby inhibiting adipogenesis [6].

Unlike WAT, brown adipose tissue (BAT) is an essential component of energy expenditure as it dissipates energy in the form of heat [7], a process known as thermogenesis. Adipose mitochondria play a pivotal role in adaptive thermogenesis, the key adipose-specific metabolic pathway that is regulated by peroxisome proliferator-activated receptor $\gamma$ coactivator-1alpha (PGC-1 $\alpha$ ) [8]. This pathway oxidizes lipids and dissipates heat energy as a result of the uncoupling of the mitochondrial electron transport chain due to ATP production by uncoupling protein 1 (UCP1). Thermogenesis is elevated in the mitochondria-rich BAT, and it is also observed in WAT, which contains brown-like cells $[9,10]$. Thermogenesis has been demonstrated to be modified by macronutrient content in the diet, dietary carbohydrate, and fat type [11, 12]. Phytochemicals like resveratrol [13] and epigallocatechin gallate [14] have been reported to 
increase energy expenditure and thermogenesis in animals and humans. Therefore, it is possible that novel therapeutic agents activating or elevating the expression of PGC- $1 \alpha$ and UCP1 would have crucial impacts on increasing the energy expenditure to ultimately prevent obesity.

Olive (Olea europaea) leaf has been widely used in traditional remedies as well as in human diet as an extract, in herbal tea and in the powder form in the European and Mediterranean countries [15]. Olive leaf extract (OLE) is marketed as a natural nutraceutical with wide-ranging health benefits. In recent years, research has mainly focused on the effects of extracts from olive leaves related to the prevention of hypertension [16], atherosclerosis [17], cancer [18], diabetes [19], and cardiovascular diseases [20,21]. Olive leaves contain several different compounds collectively termed as olive biophenols, which impart the therapeutic properties. The most abundant biophenol is oleuropein, followed by other biophenols such as verbascoside, luteolin, rutin, catechin, and hydroxytyrosol in lower quantities [22]. Our previous study demonstrated that the addition of oleuropein to HFD decreased body weight gain and improved the lipid profiles in the plasma of mice [23]. Although several studies have investigated the biochemical roles of olive leaves and olive leaves preparations, their protective effect against dietinduced obesity has never been reported. Therefore, the objective of this study was to investigate the weight-reducing effect of a well-defined OLE by supplementation in HFDinduced mice and to investigate the underlying mechanisms of this effect, with a particular focus on the expression of molecules involved in adipogenesis and thermogenesis.

\section{Materials and Method}

2.1. Materials. Dry OLE was obtained from Frutarom Switzerland Ltd. (Wädenswil, Switzerland) under the trade name of Benolea. The extract was manufactured from the dried leaves of Olea europaea L., applying an ethanol (80\%, $\mathrm{m} / \mathrm{m}$ ) extraction procedure. After a patented filtration process (EFLA Hyperpure), the crude extract was dried. Finally, $15 \%(\mathrm{~m} / \mathrm{m})$ Acaciae Gummi Ph. Eur was added as a carrier together with $<0.5 \%(\mathrm{~m} / \mathrm{m})$ of silica colloidalis anhydrica $\mathrm{Ph}$. Eur. The extract is characterized by a DER of 3-7 =1 (5 = 1). Characteristic component is $16-24 \%(\mathrm{~m} / \mathrm{m})$ oleuropein. Sibutramine was purchased from Sigma-Aldrich (MA, USA).

2.2. High-Performance Liquid Chromatography (HPLC) Anal$y$ sis of OLE. HPLC analysis was conducted using the NovaPak C18 column $(150 \mathrm{~mm} \times 3.9 \mathrm{~mm}, 60 \mathrm{~A}$, Waters Associates, Harrow, UK) at $25^{\circ} \mathrm{C}$ at a flow rate of $1 \mathrm{~mL} / \mathrm{min}$ by using a gradient mobile phase (water: methanol in 600:400 ratio) as the initial condition of the chromatography. The sample injection volume used was $10 \mu \mathrm{L}$. The absorption signal of oleuropein was examined at $233 \mathrm{~nm}$ by using the UV detector (Agilent Technologies, DE, USA).

2.3. Animal and Diets. Five-week-old male C57BL/6N mice (Orient Bio, Gyeonggi-do, Korea) were housed in a pathogenfree facility at $21 \pm 2.0^{\circ} \mathrm{C}$, with $50 \pm 5 \%$ relative humidity and a
TABLE 1: Composition of the experimental diets.

\begin{tabular}{|c|c|c|c|}
\hline Ingredients & $\begin{array}{c}\text { HFD } \\
\text { (g/kg diet) }\end{array}$ & $\begin{array}{c}\text { OLD } \\
\text { (g/kg diet) }\end{array}$ & $\begin{array}{c}\text { SD } \\
\text { (g/kg diet) }\end{array}$ \\
\hline Casein & 200 & 200 & 200 \\
\hline DL-methionine & 3 & 3 & 3 \\
\hline Corn starch & 111 & 109.5 & 110.9 \\
\hline Sucrose & 370 & 370 & 370 \\
\hline Cellulose & 50 & 50 & 50 \\
\hline Corn oil & 30 & 30 & 30 \\
\hline Lard & 170 & 170 & 170 \\
\hline Mineral mixture $^{1}$ & 42 & 42 & 42 \\
\hline Vitamin mixture $^{2}$ & 12 & 12 & 12 \\
\hline Choline bitartrate & 2 & 2 & 2 \\
\hline Cholesterol & 10 & 10 & 10 \\
\hline $\begin{array}{l}\text { tert- } \\
\text { Butylhydroquinone }\end{array}$ & 0.04 & 0.04 & 0.04 \\
\hline Olive leaf extract & - & 1.5 & - \\
\hline Sibutramine & - & - & 0.1 \\
\hline Total (g) & 1,000 & 1,000 & 1,000 \\
\hline Fat (\% calories) & 40 & 40 & 40 \\
\hline $\begin{array}{l}\text { Total energy } \\
\text { (kcal/kg diet) }\end{array}$ & 4,616 & 4,616 & 4,616 \\
\hline
\end{tabular}

${ }^{1}$ AIN-76A mineral mix.

${ }^{2}$ AIN-76A vitamin mix.

${ }^{3}$ Antioxidant agent: $0.01 \mathrm{~g} / 50 \mathrm{~g}$ lipids.

$12 \mathrm{~h}$ light/dark cycle; the mice were provided access to rodent chow and tap water ad libitum for 1 week. Thereafter, the mice were divided into the following 4 groups matched for body weight ( $n=8$ in each group): the chow diet (CD), high-fat $\operatorname{diet}(\mathrm{HFD}), 0.15 \%$ (w/w) OLE-supplemented diet (OLD), and $0.01 \%(\mathrm{w} / \mathrm{w})$ sibutramine-supplemented diet (SD) groups. The HFD consisted of $200 \mathrm{~g}$ fat $/ \mathrm{kg}$ body weight (170 g of lard and $30 \mathrm{~g}$ of corn oil) and $1 \%(\mathrm{w} / \mathrm{w})$ cholesterol. The OLD was identical to the HFD and contained $0.15 \%$ OLE. The SD was also identical to the HFD, except that it was supplemented with $0.01 \%$ sibutramine. The composition of the experimental diets including total energy ( $\mathrm{kcal} / \mathrm{kg}$ diet) is shown in Table 1. All the diets were provided in the form of pellets for 8 weeks.

The food intake was monitored daily, and body weights were recorded on a weekly basis. At the end of the experimental period, the mice were anesthetized with diethyl ether after they were fasted for $16 \mathrm{~h}$. Blood samples were drawn from the inferior vena cava into an ethylene-diamine-tetraacetic acid (EDTA)-coated tube, and the plasma samples were obtained by centrifuging the blood at $4000 \times \mathrm{g}$ for $15 \mathrm{~min}$ at $4^{\circ} \mathrm{C}$. The epididymal, retroperitoneal, mesenteric, and perirenal fat-pads were dissected, removed, weighed, and immediately snap-frozen in liquid nitrogen and stored at $-80^{\circ} \mathrm{C}$ until further use. All animal experiments were performed in accordance with the Korea Food and Drug Administration (KFDA) guidelines. All the experimental protocols were reviewed and approved by the Institutional Animal Care and Use Committee (IACUC) of the Yonsei Laboratory Animal Research Center (YLARC). 


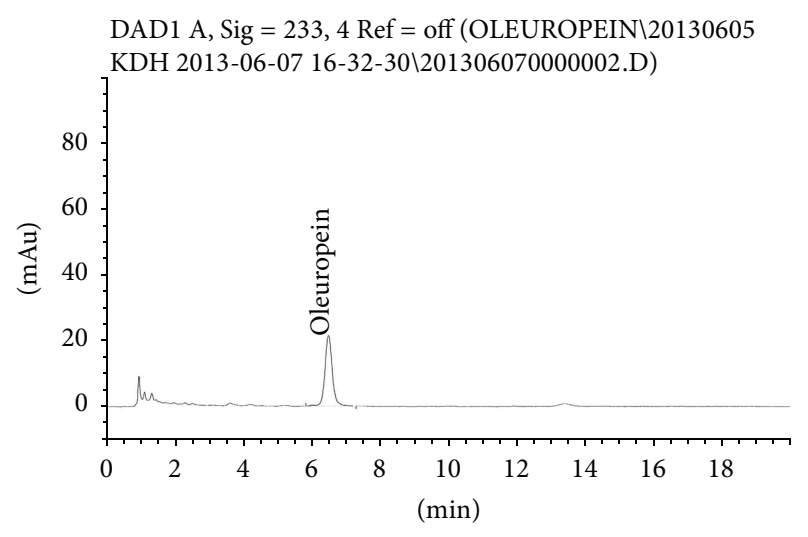

FIGURE 1: High-performance liquid chromatography (HPLC) chromatogram of the olive leaf extract (OLE). The peak was assigned based on the isolation of oleuropein.

2.4. Histological Analysis. The epididymal fat-pads were fixed in $10 \%$ buffered formalin and embedded in paraffin blocks. The paraffin blocks were sectioned and stained with hematoxylin-eosin (H\&E). The sectional areas of the epididymal fat-pads were analyzed to quantify the size of the fat droplets.

2.5. Biochemical Analysis. Plasma concentrations of total cholesterol, triglyceride, HDL cholesterol, free fatty acid, and glucose were enzymatically determined using commercial kits (Bio-Clinical System, Gyeonggi-do, South Korea). Plasma levels of LDL + VLDL cholesterol were calculated by subtracting the HDL cholesterol level from the total cholesterol level. Plasma level of leptin was measured using a commercially available mouse enzyme-linked immunosorbent assay (ELISA) kit (Millipore, MA, USA).

\subsection{RNA Extraction and Semiquantitative Reverse Transcrip- tase-Polymerase Chain Reaction (RT-PCR). Total RNA was isolated from the epididymal adipose tissue of each mouse by using TRIzol (Invitrogen, CA, USA) and was reverse- transcribed using the superscript II kit (Invitrogen) according to the manufacturer's instructions. The GenBank accession numbers of the relevant templates and the forward $(\mathrm{F})$ and reverse $(R)$ primer sequences are shown in Table 2. The PCR was programmed as follows: $10 \mathrm{~min}$ at $94^{\circ} \mathrm{C}, 30-35$ cycles of $94^{\circ} \mathrm{C}$ for $30 \mathrm{~s}, 55^{\circ} \mathrm{C}$ for $30 \mathrm{~s}, 72^{\circ} \mathrm{C}$ for $1 \mathrm{~min}$, and $10 \mathrm{~min}$ incubation at $72^{\circ} \mathrm{C}$. Then, $5 \mu \mathrm{L}$ of each PCR product was mixed with $1 \mu \mathrm{L}$ of 6 -fold concentrated loading buffer; this solution was run on a $2 \%$ agarose gel containing ethidium bromide. The band intensities were quantified using the Quantity One Analysis Software (Bio-Rad, CA, USA). The mRNA levels were normalized to that of the glyceraldehyde- 3-phosphate dehydrogenase (GAPDH) transcript.}

2.7. Western Blotting. The epididymal adipose tissue samples obtained from each mouse were homogenized in an extraction buffer containing $100 \mathrm{mM}$ Tris- $\mathrm{HCl}(\mathrm{pH}$ 7.4), $5 \mathrm{mM}$ EDTA, $50 \mathrm{mM} \mathrm{NaCl}, 50 \mathrm{mM}$ sodium pyrophosphate, $50 \mathrm{mM}$
NaF, $100 \mathrm{mM}$ orthovanadate, $1 \%$ Triton X-100, $1 \mathrm{mM}$ phenylmethanesulfonyl fluoride, $2 \mu \mathrm{g} / \mathrm{mL}$ aprotinin, $1 \mu \mathrm{g} / \mathrm{mL}$ pepstatin $\mathrm{A}$, and $1 \mu \mathrm{g} / \mathrm{mL}$ leupeptin. The homogenates were centrifuged at $1,300 \times \mathrm{g}$ for $20 \mathrm{~min}$ at $4^{\circ} \mathrm{C}$. The protein concentrations of the tissue extracts were measured by Bradford assay (Bio-Rad). The protein samples were separated by $8 \%$ sodium dodecyl sulfate (SDS)-polyacrylamide gel electrophoresis (PAGE) and then electrophoretically transferred to nitrocellulose membranes (Amersham, Buckinghamshire, UK). The nitrocellulose membranes were incubated overnight with primary antibodies (diluted $1: 1,000$ ) at $4^{\circ} \mathrm{C}$. Antibodies to the following proteins were commercially obtained from the indicated sources: $\beta$-catenin and $\beta$-actin from Santa Cruz Biotechnology (Santa Cruz, CA, USA) and extracellular signal-related kinase (ERK), phospho-ERK (Thr202/Tyr204), cyclic AMP-responsive element-binding protein (CREB), and phospho-CREB (Ser133) from Cell Signaling Technology (MA, USA). The membranes were incubated with the corresponding secondary antibodies and the immunoreactive signals were detected using a chemiluminescent detection system (Amersham), followed by quantification using the Quantity One Analysis Software (Bio-Rad).

2.8. Statistical Analysis. The results on body weight gain, plasma biochemistries, and adipocyte diameter are presented as the mean \pm standard error of mean (SEM) of 8 mice in each group. The RT-PCR and western blotting data are shown as the means \pm SEM of three independent experiments $(n=2$ or 3 per experiment) for each group, cumulatively including 8 mice. The statistical significance of difference was determined using one-way analysis of variance, followed by Duncan's multiple-range tests. All statistical analyses were performed with SPSS 21.0 software. $P \leq 0.05$ was considered statistically significant.

\section{Results}

3.1. HPLC Analysis of OLE. HPLC analysis revealed that the OLE used in the present study, Benolea, contained 16\% oleuropein (Figure 1).

\subsection{Effects of OLE on Body and Visceral Fat-Pad Weights.} HFD-fed mice showed significant increases in final body weight $(38 \%, P<0.05)$ and cumulative body weight gain $(162 \%, P<0.05)$ as compared with CD-fed mice. OLD-fed mice showed a $37 \%$ reduction in final body weight and an $80 \%$ decrease in body weight gain as compared with HFDfed mice (Figures 2(a) and 2(b)). The food intake was also significantly lower in OLD-fed mice $(-26 \%, P<0.05)$ than in HFD-fed mice during the 8-week feeding period. The food efficiency ratio (FER) $(-74 \%, P<0.05)$ of OLD-fed mice was significantly lower than that of HFD-fed mice (Figures 2(c) and $2(\mathrm{~d}))$. The cumulative caloric intake over 8 weeks was $26 \%$ less in OLD-fed mice than in HFD-fed mice (660 versus $887 \mathrm{kcal})$. The OLD group also showed significantly lower values for total visceral (epididymal, mesenteric, perirenal, and retroperitoneal) fat-pad weights $(-72 \%, P<0.05)$ than those observed in the HFD group. Histological sections from 
TABLE 2: Primer sequences and RT-PCR conditions.

\begin{tabular}{|c|c|c|c|c|}
\hline Gene description & Primers & Sequences $\left(5^{\prime} \rightarrow 3^{\prime}\right)$ & $T_{m}\left({ }^{\circ} \mathrm{C}\right)$ & Size (bp) \\
\hline \multirow{2}{*}{ Peroxisome proliferator-activated receptor $\gamma(\operatorname{PPAR} \gamma)$} & $\mathrm{F}$ & TTCGGAATCAGCTCTGTGGA & \multirow{2}{*}{55} & \multirow{2}{*}{148} \\
\hline & $\mathrm{R}$ & CCATTGGGTCAGCTCTTGTG & & \\
\hline \multirow{2}{*}{ CCAAT/enhancer binding-protein $\alpha(\mathrm{C} / \mathrm{EBP} \alpha)$} & $\mathrm{F}$ & AAGGCCAAGAAGTCGGTGGA & \multirow{2}{*}{55} & \multirow{2}{*}{189} \\
\hline & $\mathrm{R}$ & CCATAGTGGAAGCCTGATGC & & \\
\hline \multirow{2}{*}{ Leptin } & $\mathrm{F}$ & CTCCAAGGTTGTCCAGGGTT & \multirow{2}{*}{55} & \multirow{2}{*}{143} \\
\hline & $\mathrm{R}$ & AAAACTCCCCACAGAATGGG & & \\
\hline \multirow{2}{*}{ Cluster of differentiation 36 (CD36) } & $\mathrm{F}$ & ATGACGTGGCAAAGAACAGC & \multirow{2}{*}{55} & \multirow{2}{*}{160} \\
\hline & $\mathrm{R}$ & GAAGGCTCAAAGATGCCTCC & & \\
\hline \multirow{2}{*}{ Fatty acid synthase (FAS) } & $\mathrm{F}$ & TTGCCCGAGTCAGAGAACC & \multirow{2}{*}{55} & \multirow{2}{*}{171} \\
\hline & $\mathrm{R}$ & CGTCCACAATAGCTTCATAGC & & \\
\hline \multirow{2}{*}{ Wingless-type MMTV integration site family, member 10b (WNT10b) } & $\mathrm{F}$ & TTTTGGCCACTCCTCTTCCT & \multirow{2}{*}{61} & \multirow{2}{*}{183} \\
\hline & $\mathrm{R}$ & TCCTTTTCCAACCGAAAACC & & \\
\hline \multirow{2}{*}{ Secreted frizzled-related protein 5 (SFRP5) } & $\mathrm{F}$ & CTGATGGCCTCATGGAACAG & \multirow{2}{*}{55} & \multirow{2}{*}{155} \\
\hline & $\mathrm{R}$ & CTTGGTGTCCTTGCGCTTTA & & \\
\hline \multirow{2}{*}{ Galanin } & $\mathrm{F}$ & GAGCCTTGATCCTGCACTGA & \multirow{2}{*}{60} & \multirow{2}{*}{121} \\
\hline & $\mathrm{R}$ & AGTGGCTGACAGGGTCACAA & & \\
\hline \multirow{2}{*}{ Galanin receptor 1 (GalR1) } & $\mathrm{F}$ & CCAAGGGGGTATCCCAGTAA & \multirow{2}{*}{55} & 147 \\
\hline & $\mathrm{R}$ & GGCCAAACACTACCAGCGTA & & 147 \\
\hline Galanin recentor 2 (GalR2) & $\mathrm{F}$ & ATAGTGGTGCTCATGCTGGAA & 60 & 134 \\
\hline & $\mathrm{R}$ & AGGCTGGATCGAGGGTTCTA & & \\
\hline Protein kinase $\mathrm{C} \delta(\mathrm{PKC} \delta)$ & $\mathrm{F}$ & CTGAGCGCTGCAAGAAGAAC & 60 & 146 \\
\hline & $\mathrm{R}$ & TGGAAACTTTGATCCTGCACTGA & & \\
\hline Peroxisome proliferative activated recentor $\gamma$ coactivator $1 \alpha$ (PGC- $1 \alpha)$ & $\mathrm{F}$ & TAAATCTGCGGGATGATGGA & 55 & 117 \\
\hline 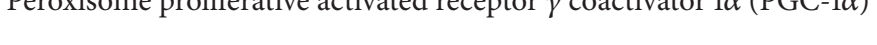 & $\mathrm{R}$ & GTTTCGTTCGACCTGCGTAA & & \\
\hline Uncoupling protein 1 (UCP1) & $\mathrm{F}$ & GGTTTTGCACCACACTCCTG & 55 & 111 \\
\hline & $\mathrm{R}$ & ACATGGACATCGCACAGCTT & & \\
\hline Cyclin D (cyc-D) & $\mathrm{F}$ & TGGGAAGTTTTGTTGGGTCA & 55 & 144 \\
\hline & $\mathrm{R}$ & TCCTTGTCCAGGTAATGCCA & & \\
\hline $\mathrm{E} 2 \mathrm{~F} 1$ & $\mathrm{~F}$ & CCTGGAGCATGTTAAAGAAG & 55 & 102 \\
\hline & $\mathrm{R}$ & CCTCGAGACCAAAGTGATAG & & \\
\hline Sirtuin 1(SIRT1) & $\mathrm{F}$ & AGCTCCTTGGAGACTGCGAT & 55 & 182 \\
\hline & $\mathrm{R}$ & ATGAAGAGGTGTTGGTGGCA & 35 & 182 \\
\hline Cytochrome $\mathrm{C}$ oxidase subunit 2 (COX2) & $\mathrm{F}$ & CCGAGTCGTTCTGCCAATAG & 55 & 159 \\
\hline ( ) & $\mathrm{R}$ & AACCCTGGTCGGTTTGATGT & & \\
\hline Mitochondrial transcription factor A (TFAM) & $\mathrm{F}$ & AGTGTGGCAGTCCATAGGCA & 55 & 123 \\
\hline & $\mathrm{R}$ & CAGTGCTTTTAGCACGCTCC & & \\
\hline Nuclear resniratory factor-1 (NRF-1) & $\mathrm{F}$ & TTTCATGGACCCAGGCATTA & 55 & 119 \\
\hline & $\mathrm{R}$ & TGGTGGCCTGAGTTTGTGTT & & \\
\hline Glyceraldehyde-3-phosphate dehydrogenase (GAPDH) & $\mathrm{F}$ & AGAACATCATCCCTGCATCC & 55 & 321 \\
\hline 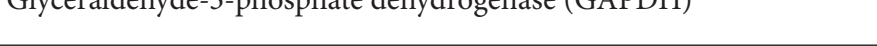 & $\mathrm{R}$ & TCCACCACCCTGTTGCTGTA & & \\
\hline
\end{tabular}

the epididymal adipose tissue of HFD-fed mice presented a greater adipocyte diameter as compared with CD-fed mice; this change in the adipocyte size was significantly reversed by OLE supplementation $(-47 \%, P<0.05)$ (Figures $2(\mathrm{e})$ and 2(f)). OLE had greater effects on lowering body weight, food intake, total visceral fat-pad weights, and adipocyte size than did sibutramine (Figures 2(a)-2(f)).

3.3. Effects of OLE on Plasma Biochemistries. OLE supplementation resulted in significantly lower concentrations of triglyceride $(-55 \%, P<0.05)$, total cholesterol $(-28 \%$, $P<0.05)$, LDL + VLDL cholesterol $(-62 \%, P<0.05)$, FFA $(-42 \%, P<0.05)$, glucose $(-17 \%, P<0.05)$, and leptin $(-69 \%, P<0.05)$ in the plasma of HFD-fed mice (Figures 3(a)-3(f)). The effect of OLE on reducing the plasma levels of triglyceride, total cholesterol, and LDL + VLDL cholesterol was significantly greater than that of sibutramine (Figures 3(a)-3(c)). OLE significantly reduced the plasma FFA and leptin levels, similar to sibutramine (Figures 3(d) and 3(f)); however, OLE was less effective in reducing the plasma glucose level than was sibutramine (Figure 3(e)). 


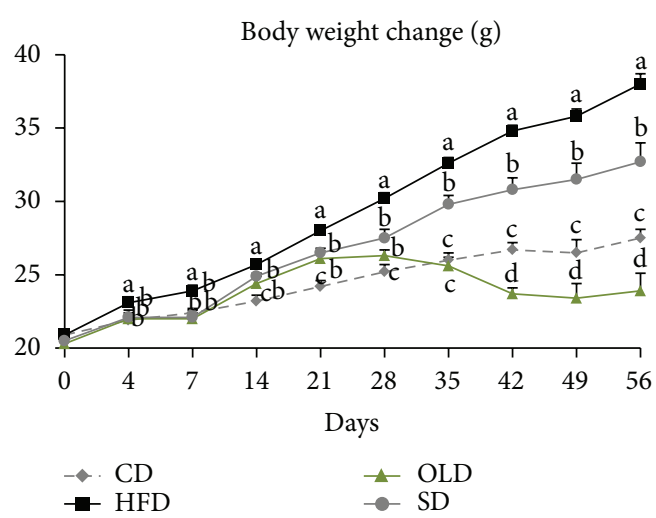

(a)
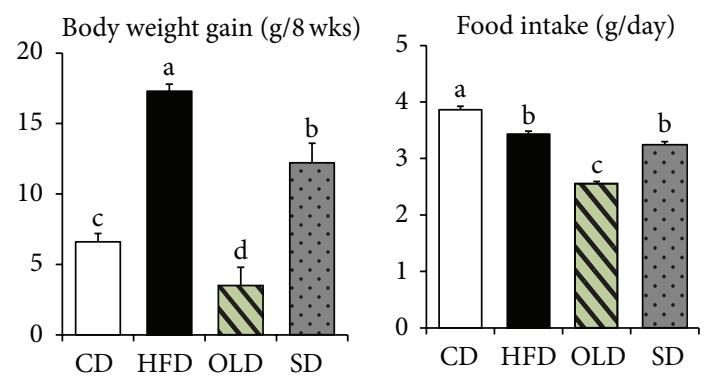

(c)

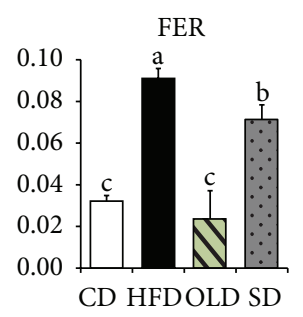

(d)

Visceral fat-pad weights $(\mathrm{g})$

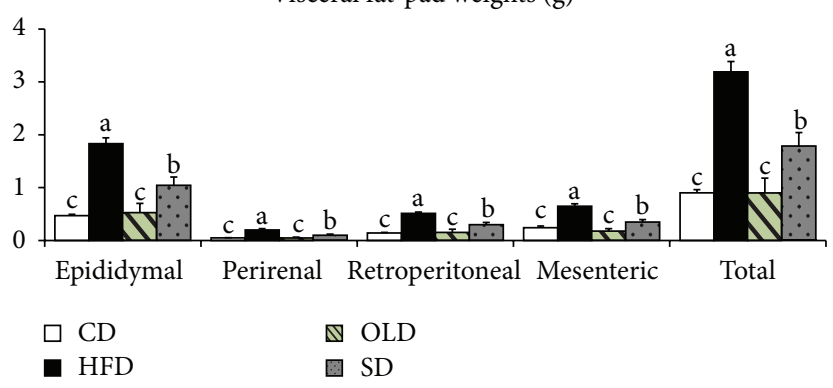

(e)

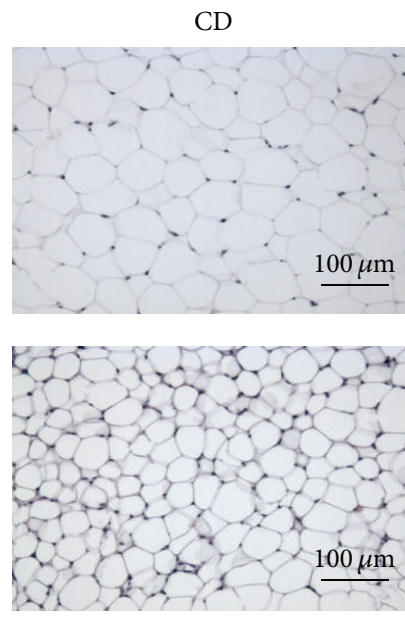

OLD
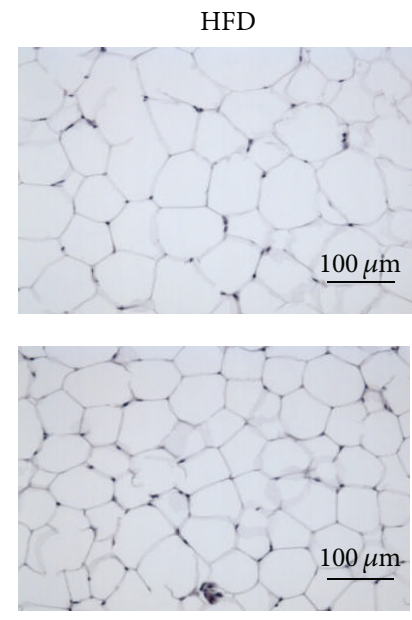

$\mathrm{SD}$

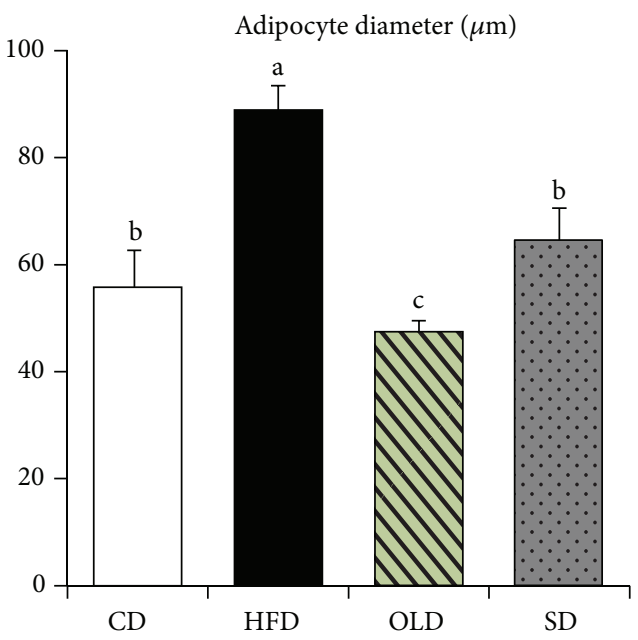

(f)

FIGURE 2: Effects of OLE on body weight gain, food efficiency ratio (FER), and visceral fat-pad weights of HFD-fed mice. Mice were fed CD, HFD, OLD, or SD for 8 weeks. Changes in the (a) body weight, (b) body weight gain, (c) food intake, (d) FER, and (e) visceral fat-pad weights. (f) Histological analysis of the epididymal adipose tissue from each group was conducted to quantify the size of adipocyte. (Left) Representative pictures of hematoxylin-eosin (H\&E)-stained fat cells from the mice epididymal adipose tissue ( $\times 100)$. (Right) Densitometric analysis of the average adipocyte diameter in the epididymal adipose tissue of mice. Values are presented as means \pm SEM $(n=8)$. Mean values indicated with different letters indicate statistical significance $(P<0.05)$; FER $=$ Body weight gain for experimental period $(\mathrm{g}) /$ food intake for experimental period (g).

3.4. Effects of OLE on the Expression of Molecules That Regulate Adipogenesis. We investigated whether OLE affected HFDinduced activation of adipogenesis in the epididymal adipose tissue of mice. In the present study, we found that OLE significantly upregulated the expression of wingless-type MMTV integration site family, member $10 \mathrm{~b}$ (WNT10b) (79\%, $P<0.05)$, and low-density lipoprotein receptor-related protein 5 (LRP5) $(26 \%, P<0.05)$ and downregulated 


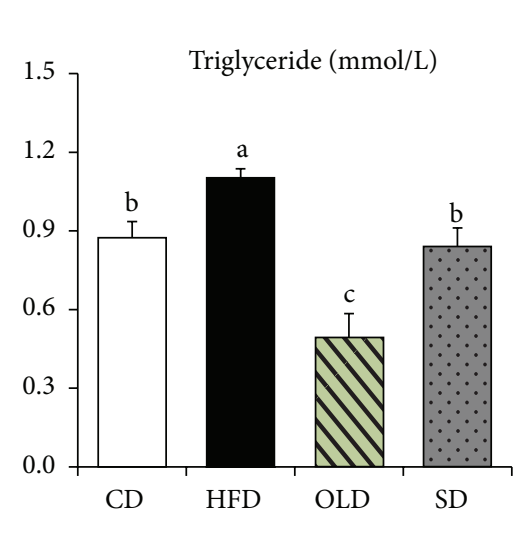

(a)

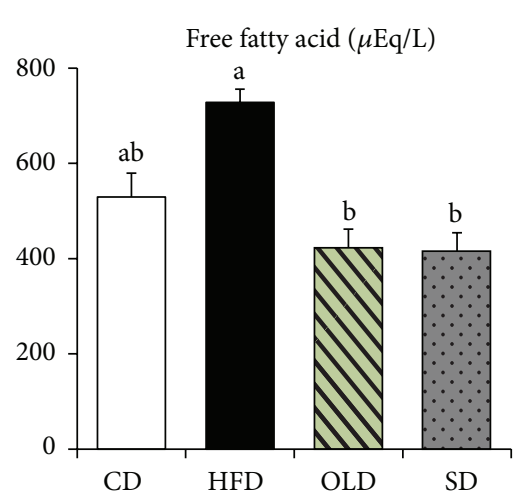

(d)

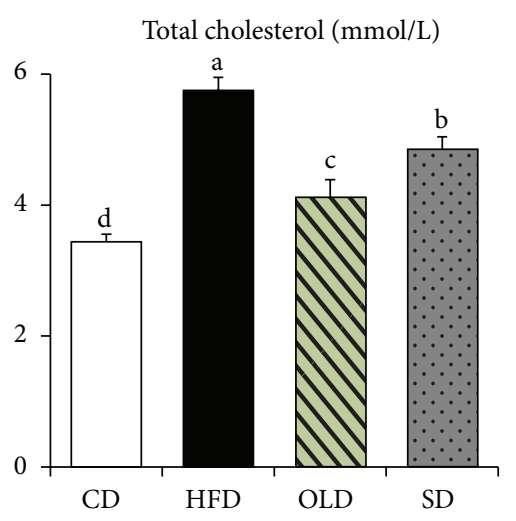

(b)

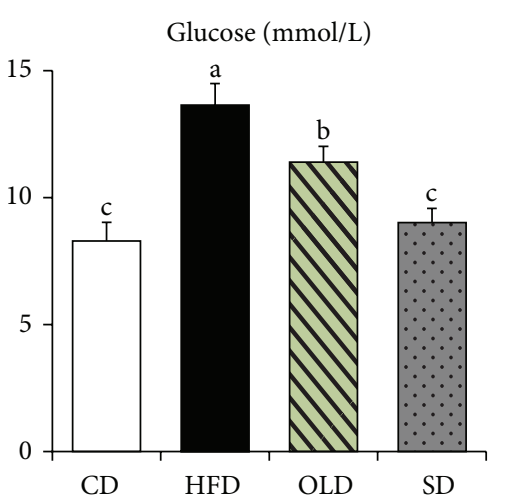

(e)

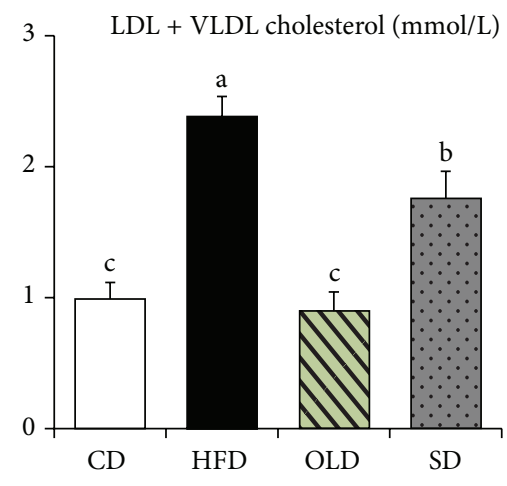

(c)

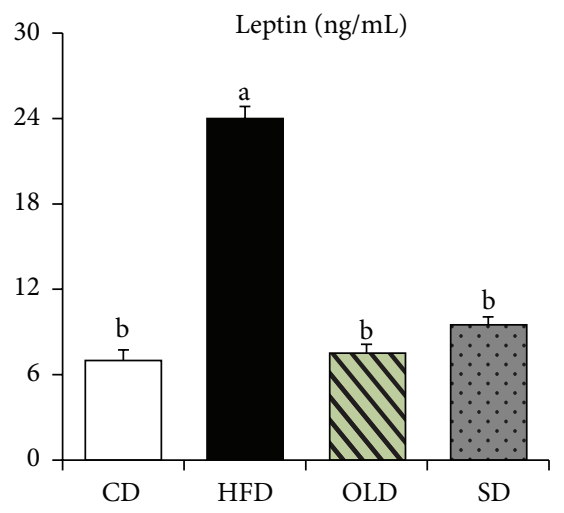

(f)

FIGURE 3: Effects of OLE on plasma levels of lipids, glucose, and leptin in HFD-fed mice. (a) Triglyceride, (b) total cholesterol, (c) LDL + VLDL cholesterol, (d) free fatty acid, (e) glucose, and (f) leptin. Bars represent the mean \pm SEM $(n=8)$. Mean values indicated with different letters indicate statistical significance $(P<0.05)$.

the expression of secreted frizzled-related protein 5 (SFRP5) $(-59 \%, P<0.05)$ in the epididymal adipose tissue of HFDfed mice (Figure 4(a)). Western blotting of the epididymal adipose tissue of mice revealed a significantly higher protein level of $\beta$-catenin $(300 \%, P<0.05)$ in OLD-fed mice relative to HFD-fed mice (Figure 4(b)). Furthermore, compared with HFD-fed mice, OLD-fed mice showed significantly lower expression of galanin $(-65 \%, P<0.05)$, galanin receptor 1 (GalR1) $(-62 \%, P<0.05)$, galanin receptor 2 (GalR2) $(-62 \%, P<0.05)$, PKC $\delta(-74 \%, P<0.05)$, cyclin $\mathrm{D}$ (Cyc-D) $(-68 \%, P<0.05)$, and E2F1 $(-25 \%, P<$ 0.05 ) in the epididymal adipose tissue of mice (Figure 4(c)). OLE supplementation resulted in decreased protein levels of phosphorylated ERK (Thr202/Tyr204) $(-38 \%, P<0.05)$ in HFD-fed mice (Figure 4(d)). The mRNA levels of $\mathrm{C} / \mathrm{EBP} \alpha$, $\operatorname{PPAR} \gamma$, and its target genes (CD36, FAS, and leptin) were significantly downregulated in OLD-fed mice as compared with those in HFD-fed mice (Figure 4(e)).

3.5. Effects of OLE on the Expression of Molecules Involved in Thermogenesis. We next assessed whether OLE can induce thermogenesis in the epididymal adipose tissue of mice. The mRNA levels of mitochondrial protein cytochrome $\mathrm{C}$ oxidase subunit 2 (COX2) $(93 \%, P<0.05)$, mitochondrial transcription factor A (TFAM) (71\%, $P<0.05)$, nuclear respiratory factor-1 (NRF-1) $(53 \%, P<0.05)$, sirtuin 1 (SIRT1) (87\%, $P<0.05)$, PGC- $1 \alpha(89 \%, P<0.05)$, and UCP1 $(77 \%$, $P<0.05)$ were significantly elevated in OLD-fed mice than in HFD-fed mice (Figure 5(a)). OLE supplementation increased the protein level of phosphorylated CREB (450\%, $P<0.05)$ in the epididymal adipose tissue of HFD-fed mice (Figure 5(b)).

\section{Discussion}

OLE is best known for its blood pressure-lowering effect in the global market of functional food industry. In 2008, OLE, under the trade name Benolea, was approved by KFDA as a health functional food that exerts blood pressure-lowering effect at a daily recommended dose of 500-1000 mg. In addition, a clinical trial conducted by Perrinjaquet-Moccetti et al. confirmed that no adverse event was observed at a daily given dose of $1000 \mathrm{mg}$ [21]. The concentration of OLE (0.15\%) used in the present study was in the same range as it was equivalent to an intake of approximately $732 \mathrm{mg} / 60 \mathrm{~kg}$ human body weight, when calculated on the basis of normalization to the body surface area as described by the recommendations by Reagan-Shaw et al. [24] and the US Food and Drug Administration (http://www.fda.gov/cder/cancer/animalframe.htm). 

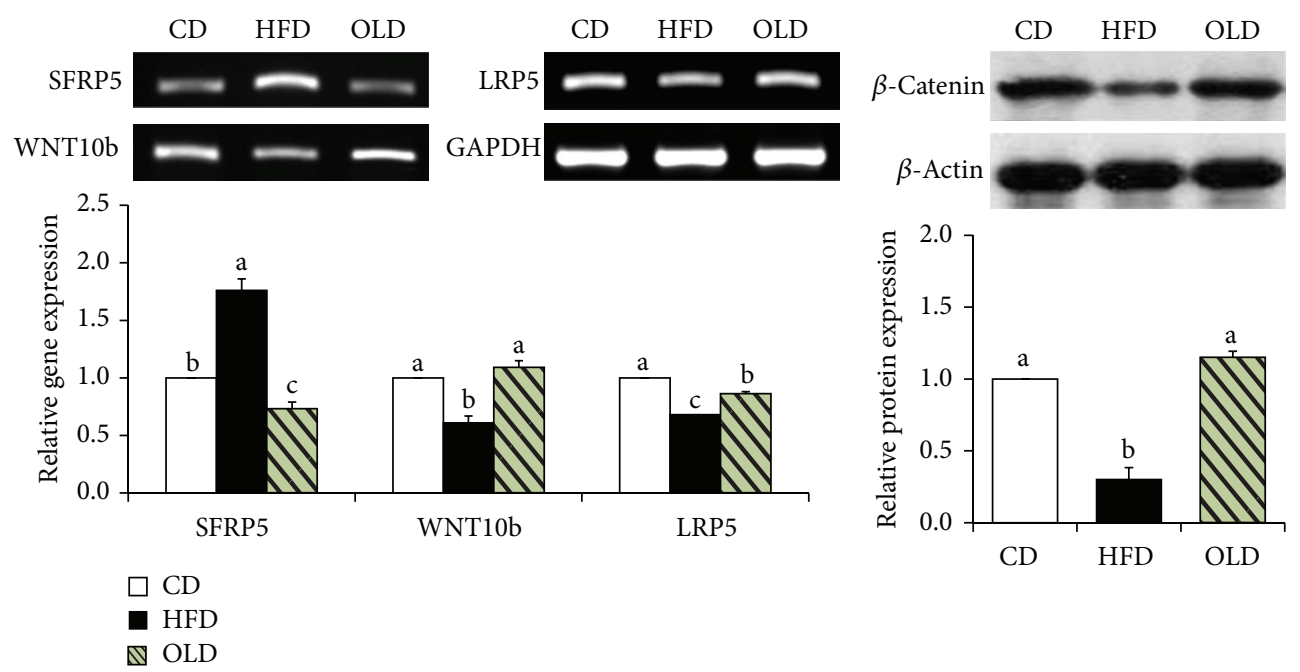

(a)
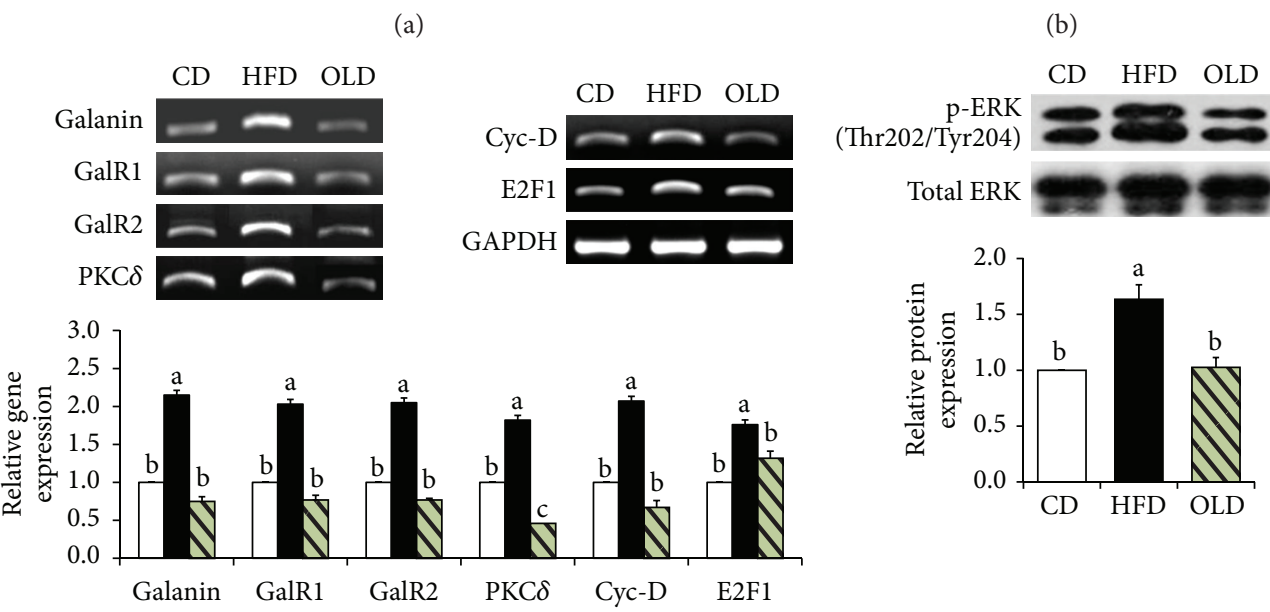
$\square \mathrm{CD}$
HFD
$\mathbb{Q}$ OLD

(c)

(d)
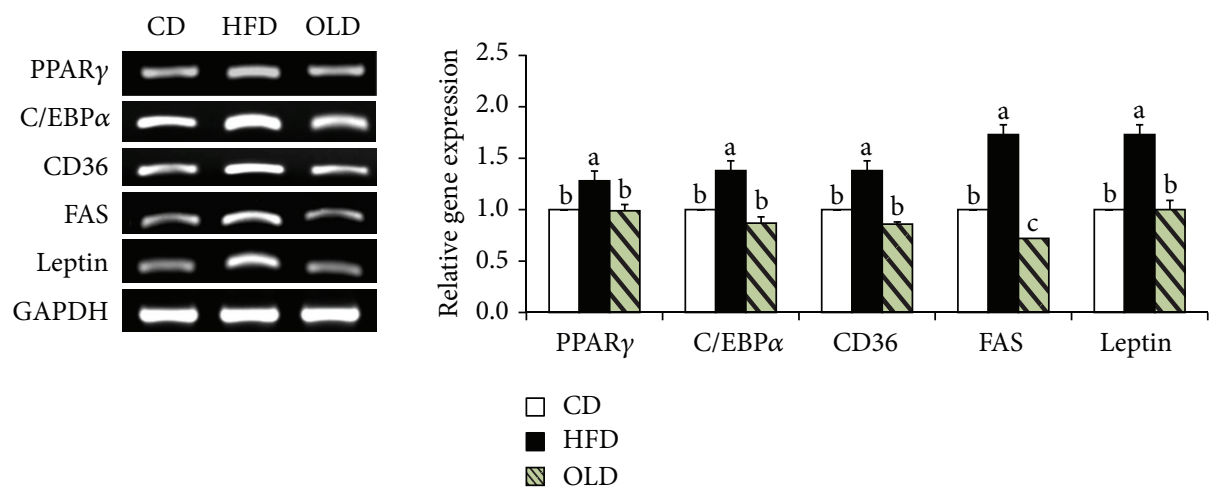

(e)

FIGURE 4: Effects of OLE on genes regulating adipogenesis in the epididymal adipose tissue of HFD-fed mice. (a) Gene expression of SFRP5, WNT10b, and LRP5, (b) protein levels of $\beta$-catenin, (c) mRNA expression of genes involved in the galanin-mediated signaling pathway, (d) protein levels of $\mathrm{p}$-ERK and total ERK, (e) expression of $\mathrm{PPAR} \gamma 2, \mathrm{C} / \mathrm{EBP} \alpha$, and their target genes. Reverse transcriptase-polymerase chain reaction (RT-PCR) data represent the relative density normalized to that of glyceraldehyde-3-phosphate dehydrogenase (GAPDH). Protein levels were normalized to the $\beta$-actin level. Data represent the results of three independent experiments $(n=2$ or 3 per experiment); $P<0.05$ indicates statistical significance. Values are the means \pm SEM, $n=8$ for each group. 


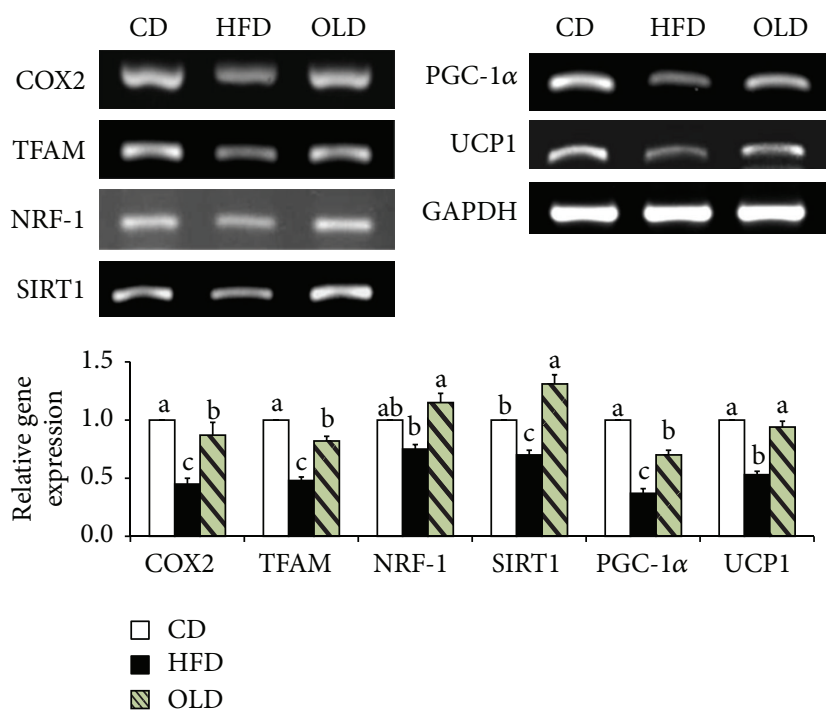

(a)

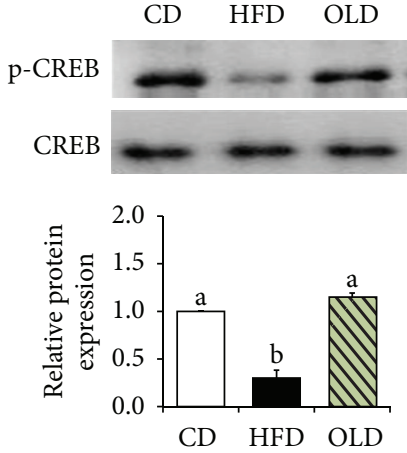

(b)

Figure 5: Effects of OLE on the expression of genes involved in thermogenesis in the epididymal adipose tissue of HFD-fed mice. (a) The expression of genes involved in uncoupled respiration and mitochondrial biogenesis was determined by RT-PCR and normalized to that of GAPDH; (b) protein levels of p-CREB and total CREB were determined by western blotting and normalized to $\beta$-actin protein levels. Data represent the results of three independent experiments $(n=2$ or 3 per experiment); $P<0.05$ indicates statistical significance. Values are the means \pm SEM, $n=8$ for each group.

Sibutramine is a monoamine-reuptake inhibitor [25] which was approved as an antiobesity drug by the FDA in 1997 and was marketed until 2010. In the present study, sibutramine was used as a positive control to evaluate the antiobesity effects of OLE.

OLE significantly decreased visceral fat-pad weight and plasma levels of triglyceride and FFA in HFD-fed mice. The decreased visceral fat accumulation might result in the reduced plasma level of FFA. The lower content of FFA, which flows into the liver through the portal vein, may cause less triglyceride synthesis in the liver, resulting in the decreased plasma level of triglyceride in OLD-fed mice. Histological analysis revealed a significantly decreased adipocyte size and an increased number of adipocyte in the OLD group than in the HFD group.

Several olive leaf constituents have been reported to exert beneficial effects against obesity both in vitro and in vivo. Oleuropein $[23,26]$, hydroxytyrosol [26, 27], luteolin [28], apigenin [29, 30], rutin [31], and caffeic acid [32] were found to decrease the accumulation of intracellular lipid, as detected by Oil Red $\mathrm{O}$ staining, and the expression of adipogenic transcription factors such as PPAR $\gamma$ and $\mathrm{C} / \mathrm{EBP} \alpha$ in 3T3L1 cells. Hydroxytyrosol also exerts beneficial effects on the promotion of mitochondrial biogenesis via stimulation of the PGC- $1 \alpha$ and its downstream target genes in 3T3-L1 cells [27]. Oleuropein and rutin decreased body weight gain and improved plasma lipid profiles and hepatic steatosis in HFDfed mice [23, 31]. Caffeic acid also exhibited antiobesity effects by reducing body and visceral fat-pad weights, plasma levels of lipids, and obesity-related hormones such as leptin and insulin in HFD-fed mice [32]. On the basis of the results of these studies, we speculate that the weight-lowering effects of
OLE can be derived from the combination of various weightsuppressing components.

Oleuropein, the bitter principle in olive leaf, accounted for $16 \%$ of the OLE used in this study. In our previous research, $0.03 \%$ oleuropein supplementation significantly reduced body weight gain $(-55 \%)$ and plasma lipid levels in HFD-fed mice for 10 weeks [23]. In the present study, OLD (0.15\% OLE-supplemented diet) contained $0.024 \%$ oleuropein and significantly decreased body weight gain $(-80 \%)$ and obesity-related plasma biomarkers in mice after 8 weeks of feeding. Although OLD in the present study contained less oleuropein and was fed for a shorter period, it exerted better weight-lowering effects than those exhibited by oleuropein-supplemented diet in our previous study [23]. In addition, OLE significantly reduced food intake in the present study, whereas oleuropein alone did not affect food intake in mice [23]. Therefore, we suggest that the body weight-lowering effect of OLE can be derived not only from oleuropein but also from other active components present in olive leaves that may act concomitantly to reduce food intake and body weight gain.

OLE significantly reduced food intake by $26 \%$ in HFD-fed mice for 8 weeks. Several animal studies on OLE investigated its effects on glucose metabolism, ultraviolet B irradiationinduced skin changes, and wound healing [33-35]. Unfortunately, none of the studies presented data for daily food intake. It is well-known that GLP-1 is a satiety-signaling hormone that inhibits food intake by upregulating the expression of anorexigenic neuropeptides such as proopiomelanocortin (POMC) and cocaine- and amphetamine-regulated transcript (CART) [36]. In the present study, the plasma GLP1 level was not measured because freshly collected plasma 
samples were not treated with dipeptidyl peptidase IV (DPP IV) inhibitor; without DPP IV inhibitor, GLP-1 is rapidly degraded in plasma. Green et al. demonstrated that oral gavage of dichloromethane extract of olive leaves improved glucose metabolism by significantly increasing plasma GLP1 concentrations in mice [33]. Among the constituents of OLE, apigenin is known to inhibit food intake at the dosage of $0.05 \%$ by increasing the expression of POMC and CART in HFD-fed mice [29]. OLD used in the present study may contain much less apigenin than $0.05 \%$, as, in an earlier report, leaf extract of Olea europaea L. contained $1.37 \%$ apigenin [37]. Further investigation is needed to confirm whether the food intake-reducing effect of OLE is exerted by its apigenin component.

Food efficiency ratio (FER), which is the ratio of body weight gain $(\mathrm{g})$ to food intake $(\mathrm{g})$, assesses utilization of food consumed. The unchanged FER demonstrates that the weight-lowering effect of a certain antiobesity agent is completely attributable to reduction in food intake. In the present study, OLE significantly decreased FER in HFDfed mice, indicating that weight-lowering effect of OLE is mediated not only by the reduction of food intake but also by its direct effects on adipocytes. The effect of OLE in reducing the expression of adipogenic genes could be derived from both the direct inhibition of adipogenesis and the reduction of total caloric intake. PPAR $\gamma$ and $\mathrm{C} / \mathrm{EBP} \alpha$ [38] are the chief regulators that act synergistically to induce the expression of downstream target genes of adipogenesis, including FAS, CD36, and leptin. Animal studies have reported that WNT10b [4] and galanin [5] played important roles in regulating the expression of $\operatorname{PPAR} \gamma 2$ and $\mathrm{C} / \mathrm{EBP} \alpha$. WNTs, secreted proteins that act through autocrine and paracrine mechanisms, serve as a functional "brake" during preadipocyte recruitment into the differentiation program [3]. Of the 19 possible WNTs, WNT10b has been most clearly implicated as the endogenous WNT involved in regulating adipogenesis [39]. HFD decreased the binding of WNT10b to FZD receptors and to LRP5/6 coreceptors, leading to the activation of the cytoplasmic $\beta$-catenin degradation [6]. The decreased cytosolic accumulation and nuclear translocation of $\beta$-catenin led to decreased transcriptional coactivation of the T-cell factor (TCF)/lymphoid-enhancer factor (LEF) transcription factors, and eventually, upregulated the expression of PPAR $\gamma$ and $\mathrm{C} / \mathrm{EBP} \alpha$ [40]. OLE significantly reversed the HFD-induced decrease in the expression of WNT10b and LRP5, which may be associated with increased cytosolic accumulation of $\beta$-catenin.

In addition, it is noteworthy that the WNT signaling pathway is regulated by endogenous WNT inhibitors [3]. SFRP5, a WNT inhibitor, directly binds to and sequesters WNT10b from FZD receptors. Epigenetic activation of SFRP5 in WAT increased susceptibility to obesity in HFD-fed mice [41]. In the present study, SFRP5 expression was significantly reduced in the epididymal adipose tissue of OLD-fed mice than in HFD-fed mice. Therefore, we presume that OLEmediated downregulation of WNT10b inhibitor, SFRP5, and upregulation of the ligand, WNT10b, may be related to the increased cytosolic accumulation of $\beta$-catenin and thus the reduction in adipogenesis and visceral adiposity.
The galanin-mediated signaling pathway is also involved in the regulation of adipogenesis. Galanin, a 29/30-residue neuropeptide, is expressed and widely distributed in the central nervous system [42]. However, recent studies have revealed that galanin expression has also been observed in peripheral tissues such as visceral adipose tissue and stomach [5]. Our previous study demonstrated that the expression of galanin, its receptors, and other genes involved in galaninmediated signaling pathway was significantly elevated in the epididymal adipose tissues of HFD-fed mice [5]. Upon prolonged HFD consumption, GalR1 stimulated the mitogenactivated protein kinase activity in a PKC-independent manner and activated 1/2 ERKs. Activation of GalR2 increased the expression of phospholipase C (PLC) which catalyzes the cleavage of phosphatidylinositol 4,5-bisphosphate into inositol 1,4,5-triphosphate and diacyl glycerol, a PKC activator. Subsequently, PKC $\delta$ induced the activation of ERK, which upregulated the expression of PPAR $\gamma$ and C/EBP $\alpha$. In the present study, OLE significantly reversed HFD-induced elevation of the expression of genes (GalR1, GalR2, PKC $\delta$, and ERK) in the epididymal adipose tissue of mice. Therefore, the effect of OLE on the reduction of visceral fat-pad weights is presumed to be associated with the downregulation of genes related to galanin-mediated adipogenesis in HFD-fed mice.

In addition to the inhibition of fat accumulation in WAT, improvement of the capacity of thermogenesis can also account for the body fat-lowering effect of OLE. Adaptive thermogenesis is defined as heat production in response to environmental temperature or diet, which protects the organism from exposure to cold or regulates the energy balance after changes in the diet [1]. Mitochondria, the organelles that convert food to carbon dioxide, water, and ATP, are indispensable for energy dissipation. Activation of UCP1, a mitochondrial proton transporter, enhances uncoupled respiration and thereby results in dissipation of oxidation energy as heat [1]. Galanin receptors [5] and SIRT1 [43] are known to reverse obesity-induced downregulation of UCP1 expression in WAT. Our previous study demonstrated that the HFD-induced overexpression of GalR1 and GalR2 inhibited cAMP, which in turn reduced protein kinase A (PKA), in the epididymal and subcutaneous adipose tissues of mice. Decreased PKA downregulated the phosphorylation of CREB, leading to decreased gene expression of PGC-1 $\alpha$ [5]. SIRT1, which is responsible for deacetylating and activating PGC- $1 \alpha$ at multiple lysine sites, was downregulated by HFD in the adipose tissue of mice [44]. Consequently, HFDinduced downregulation of PGC- $1 \alpha$ decreased the expression of UCP1 and eventually suppressed uncoupled respiration. In the present study, OLE simultaneously reversed the HFDinduced upregulation of GalR1 and GalR2 expression and downregulation of SIRT1, PGC-1 $\alpha$, and UCP1 expression in the epididymal adipose tissue of mice. Therefore, we suggest that the visceral fat-pad weight-lowering effects of OLE can be associated with the elevation of the gene expression involved in uncoupled respiration in the visceral adipose tissue of HFD-fed mice.

The coordination of mitochondrial biogenesis with uncoupled respiration is crucial in increasing the capacity 
of thermogenesis [1]. PGC-1 $\alpha$ is a potent inducer of mitochondrial biogenesis. Shadel and Clayton demonstrated that PGC- $1 \alpha$ led to an activation of nuclear respiratory factor-1 (NRF-1), which binds to and activates the gene promoter of the mitochondrial electron transport system such as COX2. Another target of NRF-1 is TFAM, which translocates into mitochondria and initiates the transcription and replication of the mitochondrial DNA [45]. OLE significantly increased the mRNA expression of genes involved in mitochondrial biogenesis (PGC-1 $\alpha$, NRF-1, COX2, and TFAM) in the epididymal adipose tissue of HFD-fed mice. Accordingly, we presume that the visceral adiposity-suppressing effects of OLE may be linked to the increased mitochondrial biogenesis-related genes in the epididymal adipose tissue of mice.

In conclusion, OLE significantly decreased body weight gain, visceral fat-pad weights, and plasma lipid levels in HFDfed mice. These beneficial effects against obesity in mice appear to be mediated, at least in part, through downregulating the expression of molecules involved in adipogenesis and upregulating the expression of molecules involved in thermogenesis in the visceral adipose tissue of HFD-fed mice. Taken together, our results suggest that supplementation with OLE might be helpful to combat or prevent obesity.

\section{Abbreviations}

$\mathrm{C} / \mathrm{EBP} \alpha: \quad \mathrm{CCAAT} /$ enhancer-binding protein alpha

CD: $\quad$ Chow diet

CD36: Cluster of differentiation 36

CREB: cAMP responsive element-binding protein

Cyc-D: Cyclin D

COX2: $\quad$ Cytochrome $\mathrm{C}$ oxidase subunit 2

ERK: Extracellular signal-regulated kinase 1/2

FAS: $\quad$ Fatty acid synthase

FFA: $\quad$ Free fatty acids

GalR1: Galanin receptor 1

GalR2: Galanin receptor 2

GAPDH: Glyceraldehyde-3-phosphate dehydrogenase

HFD: High-fat diet

NRF-1: Nuclear respiratory factor-1

OLE: Olive leaf extract

PGC1 $\alpha$ : Peroxisome proliferator-activated receptor gamma coactivator lalpha

PPAR $\gamma$ : Peroxisome proliferator-activated receptor gamma

PKC $\delta$ : $\quad$ Protein kinase C delta

SFRP5: Secreted frizzled-related protein 5

SIRT1: $\quad$ Sirtuin 1

TFAM: Mitochondrial transcription factor A

UCP1: Uncoupling protein 1

WNT10b: Wingless-type MMTV integration site family, member $10 \mathrm{~b}$.

\section{Conflict of Interests}

The authors declare that there is no conflict of interests regarding the publication of this paper.

\section{Acknowledgments}

This research was supported by the MOTIE (The Ministry of Trade, Industry and Energy), Republic of Korea, under the Research and Business Development (R\&BD) support program (Grant no. N0000869) supervised by the KIAT (Korea Institute for Advancement of Technology), and by the SRC program (Center for Food and Nutritional Genomics, Grant no. 2008-0062618) of the National Research Foundation of Korea funded by the Ministry of Education, Science and Technology.

\section{References}

[1] B. B. Lowell and B. M. Spiegelman, "Towards a molecular understanding of adaptive thermogenesis," Nature, vol. 404, no. 6778, pp. 652-660, 2000.

[2] W. P. Cawthorn, E. L. Scheller, and O. A. MacDougald, "Adipose tissue stem cells: the great WAT hope," Trends in Endocrinology \& Metabolism, vol. 23, no. 6, pp. 270-277, 2012.

[3] T. C. Prestwich and O. A. MacDougald, "Wnt/ $\beta$-catenin signaling in adipogenesis and metabolism," Current Opinion in Cell Biology, vol. 19, no. 6, pp. 612-617, 2007.

[4] W. S. Wright, K. A. Longo, V. W. Dolinsky et al., "Wnt10b inhibits obesity in ob/ob and agouti mice," Diabetes, vol. 56, no. 2, pp. 295-303, 2007.

[5] A. Kim and T. Park, "Diet-induced obesity regulates the galanin-mediated signaling cascade in the adipose tissue of mice," Molecular Nutrition and Food Research, vol. 54, no. 9, pp. 1361-1370, 2010.

[6] C. Christodoulides, C. Lagathu, J. K. Sethi, and A. Vidal-Puig, "Adipogenesis and WNT signalling," Trends in Endocrinology and Metabolism, vol. 20, no. 1, pp. 16-24, 2009.

[7] J. Boucher, M. A. Mori, K. Y. Lee et al., "Impaired thermogenesis and adipose tissue development in mice with fatspecific disruption of insulin and IGF-1 signalling," Nature Communications, vol. 3, article 902, 2012.

[8] P. Puigserver, Z. Wu, C. W. Park, R. Graves, M. Wright, and B. M. Spiegelman, "A cold-inducible coactivator of nuclear receptors linked to adaptive thermogenesis," Cell, vol. 92, no. 6, pp. 829839, 1998.

[9] P. Seale, H. M. Conroe, J. Estall et al., "Prdm16 determines the thermogenic program of subcutaneous white adipose tissue in mice," The Journal of Clinical Investigation, vol. 121, no. 1, pp. 96105, 2011.

[10] H. Wang, Y. Zhang, E. Yehuda-Shnaidman et al., "Liver X receptor $\alpha$ is a transcriptional repressor of the uncoupling protein 1 gene and the brown fat phenotype," Molecular and Cellular Biology, vol. 28, no. 7, pp. 2187-2200, 2008.

[11] V. M. Rodríguez, M. P. Portillo, C. Picó, M. Teresa Macarulla, and A. Palou, "Olive oil feeding up-regulates uncoupling protein genes in rat brown adipose tissue and skeletal muscle," The American Journal of Clinical Nutrition, vol. 75, no. 2, pp. 213220, 2002.

[12] S. Samec, J. Seydoux, and A. G. Dulloo, "Post-starvation gene expression of skeletal muscle uncoupling protein 2 and uncoupling protein 3 in response to dietary fat levels and fatty acid composition: a link with insulin resistance," Diabetes, vol. 48, no. 2, pp. 436-441, 1999. 
[13] G. Alberdi, V. M. Rodriguez, J. Miranda, M. T. Macarulla, I. Churruca, and M. P. Portillo, "Thermogenesis is involved in the body-fat lowering effects of resveratrol in rats," Food Chemistry, vol. 141, no. 2, pp. 1530-1535, 2013.

[14] A. G. Dulloo, C. Duret, D. Rohrer et al., "Efficacy of a green tea extract rich in catechin polyphenols and caffeine in increasing 24-h energy expenditure and fat oxidation in humans," The American Journal of Clinical Nutrition, vol. 70, no. 6, pp. 1040$1045,1999$.

[15] S. N. El and S. Karakaya, "Olive tree (Olea europaea) leaves: potential beneficial effects on human health," Nutrition Reviews, vol. 67, no. 11, pp. 632-638, 2009.

[16] M. T. Khayyal, M. A. El-Ghazaly, D. M. Abdallah, N. N. Nassar, S. N. Okpanyi, and M. H. Kreuter, "Blood pressure lowering effect of an olive leaf extract (Olea europaea) in L-NAME induced hypertension in rats," Arzneimittel-Forschung, vol. 52, no. 11, pp. 797-802, 2002.

[17] L. Wang, C. Geng, L. Jiang et al., "The anti-atherosclerotic effect of olive leaf extract is related to suppressed inflammatory response in rabbits with experimental atherosclerosis," European Journal of Nutrition, vol. 47, no. 5, pp. 235-243, 2008.

[18] L. Abaza, T. P. N. Talorete, P. Yamada, Y. Kurita, M. Zarrouk, and H. Isoda, "Induction of growth inhibition and differentiation of human leukemia HL-60 cells by a Tunisian gerboui olive leaf extract," Bioscience, Biotechnology and Biochemistry, vol. 71, no. 5, pp. 1306-1312, 2007.

[19] A. Eidi, M. Eidi, and R. Darzi, "Antidiabetic effect of Olea europaea L. in normal and diabetic rats," Phytotherapy Research, vol. 23, no. 3, pp. 347-350, 2009.

[20] H. Poudyal, F. Campbell, and L. Brown, "Olive leaf extract attenuates cardiac, hepatic, and metabolic changes in high carbohydrate-, high fat-fed rats," The Journal of Nutrition, vol. 140, no. 5, pp. 946-953, 2010.

[21] T. Perrinjaquet-Moccetti, A. Busjahn, C. Schmidlin, A. Schmidt, B. Bradl, and C. Aydogan, "Food supplementation with an olive (Olea europaeaL.) leaf extract reduces blood pressure in borderline hypertensive monozygotic twins," Phytotherapy Research, vol. 22, no. 9, pp. 1239-1242, 2008.

[22] R. Japón-Luján, J. M. Luque-Rodríguez, and M. D. L. de Castro, "Dynamic ultrasound-assisted extraction of oleuropein and related biophenols from olive leaves," Journal of Chromatography A, vol. 1108, no. 1, pp. 76-82, 2006.

[23] Y. Kim, Y. Choi, and T. Park, "Hepatoprotective effect of oleuropein in mice: mechanisms uncovered by gene expression profiling," Biotechnology Journal, vol. 5, no. 9, pp. 950-960, 2010.

[24] S. Reagan-Shaw, M. Nihal, and N. Ahmad, "Dose translation from animal to human studies revisited," The FASEB Journal, vol. 22, no. 3, pp. 659-661, 2008.

[25] C. Gundlah, K. F. Martin, D. J. Heal, and S. B. Auerbach, "In vivo criteria to differentiate monoamine reuptake inhibitors from releasing agents: sibutramine is a reuptake inhibitor," The Journal of Pharmacology and Experimental Therapeutics, vol. 283, no. 2, pp. 581-591, 1997.

[26] R. Drira, S. Chen, and K. Sakamoto, "Oleuropein and hydroxytyrosol inhibit adipocyte differentiation in 3 T3-L1 cells," Life Sciences, vol. 89, no. 19-20, pp. 708-716, 2011.

[27] J. Hao, W. Shen, G. Yu et al., "Hydroxytyrosol promotes mitochondrial biogenesis and mitochondrial function in 3T3L1 adipocytes," The Journal of Nutritional Biochemistry, vol. 21, no. 7, pp. 634-644, 2010.
[28] H. S. Park, S. H. Kim, Y. S. Kim et al., "Luteolin inhibits adipogenic differentiation by regulating PPAR $\gamma$ activation," BioFactors, vol. 35, no. 4, pp. 373-379, 2009.

[29] H. J. Myoung, G. Kim, and K. W. Nam, "Apigenin isolated from the seeds of Perilla frutescens britton var crispa (Benth.) inhibits food intake in C57BL/6J mice," Archives of Pharmacal Research, vol. 33, no. 11, pp. 1741-1746, 2010.

[30] M. Ono and K. Fujimori, "Antiadipogenic effect of dietary apigenin through activation of AMPK in 3T3-L1 cells," Journal of Agricultural and Food Chemistry, vol. 59, no. 24, pp. 1334613352, 2011.

[31] C. L. Hsu, C. H. Wu, S. L. Huang, and G. C. Yen, "Phenolic compounds rutin and o-coumaric acid ameliorate obesity induced by high-fat diet in rats," Journal of Agricultural and Food Chemistry, vol. 57, no. 2, pp. 425-431, 2009.

[32] A. S. Cho, S. M. Jeon, M. J. Kim et al., "Chlorogenic acid exhibits anti-obesity property and improves lipid metabolism in high-fat diet-induced-obese mice," Food and Chemical Toxicology, vol. 48, no. 3, pp. 937-943, 2010.

[33] E. P. Rafferty, A. R. Wylie, C. T. Elliott, O. P. Chevallier, D. J. Grieve, and B. D. Green, "In vitro and in vivo effects of natural putative secretagogues of glucagon-like peptide-1 (GLP1)," Scientia Pharmaceutica, vol. 79, no. 3, pp. 615-621, 2011.

[34] M. Sumiyoshi and Y. Kimura, "Effects of olive leaf extract and its main component oleuroepin on acute ultraviolet $\mathrm{B}$ irradiation-induced skin changes in C57BL/6J mice," Phytotherapy Research, vol. 24, no. 7, pp. 995-1003, 2010.

[35] U. Koca, I. Süntar, E. K. Akkol, D. Yilmazer, and M. Alper, "Wound repair potential of Olea europaea L. leaf extracts revealed by in vivo experimental models and comparative evaluation of the extracts' antioxidant activity," Journal of Medicinal Food, vol. 14, no. 1-2, pp. 140-146, 2011.

[36] E. Valassi, M. Scacchi, and F. Cavagnini, "Neuroendocrine control of food intake," Nutrition, Metabolism and Cardiovascular Diseases, vol. 18, no. 2, pp. 158-168, 2008.

[37] O. Benavente-García, J. Castillo, J. Lorente, A. Ortuño, and J. A. Del Rio, "Antioxidant activity of phenolics extracted from Olea europaea L. leaves," Food Chemistry, vol. 68, no. 4, pp. 457-462, 2000.

[38] Z. Wu, E. D. Rosen, R. Brun et al., "Cross-regulation of $\mathrm{C} / \mathrm{EBP} \alpha$ and PPAR $\gamma$ controls the transcriptional pathway of adipogenesis and insulin sensitivity," Molecular Cell, vol. 3, no. 2, pp. 151-158, 1999.

[39] C. Lagathu, C. Christodoulides, S. Virtue et al., "Dact1, a nutritionally regulated preadipocyte gene, controls adipogenesis by coordinating the wnt $/ \beta$-catenin signaling network," Diabetes, vol. 58, no. 3, pp. 609-619, 2009.

[40] R. T. Moon, A. D. Kohn, G. V. de Ferrari, and A. Kaykas, "WNT and $\beta$-catenin signalling: diseases and therapies," Nature Reviews Genetics, vol. 5, no. 9, pp. 691-701, 2004.

[41] R. A. Koza, L. Nikonova, J. Hogan et al., "Changes in gene expression foreshadow diet-induced obesity in genetically identical mice," PLoS Genetics, vol. 2, no. 5, article e81, 2006.

[42] Y. Seta, S. Kataoka, T. Toyono, and K. Toyoshima, "Expression of galanin and the galanin receptor in rat taste buds," Archives of Histology and Cytology, vol. 69, no. 4, pp. 273-280, 2006.

[43] J. T. Rodgers, C. Lerin, W. Haas, S. P. Gygi, B. M. Spiegelman, and P. Puigserver, "Nutrient control of glucose homeostasis through a complex of PGC-1 $\alpha$ and SIRT1," Nature, vol. 434, no. 7029, pp. 113-118, 2005. 
[44] M. Lagouge, C. Argmann, Z. Gerhart-Hines et al., "Resveratrol improves mitochondrial function and protects against metabolic disease by activating SIRT1 and PGC-1 $\alpha$," Cell, vol. 127, no. 6, pp. 1109-1122, 2006.

[45] G. S. Shadel and D. A. Clayton, "Mitochondrial transcription initiation. Variation and conservation," The Journal of Biological Chemistry, vol. 268, no. 22, pp. 16083-16086, 1993. 


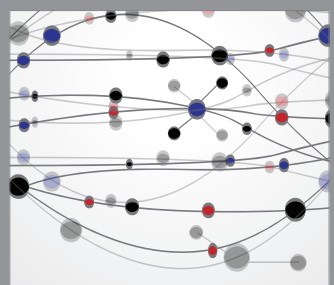

The Scientific World Journal
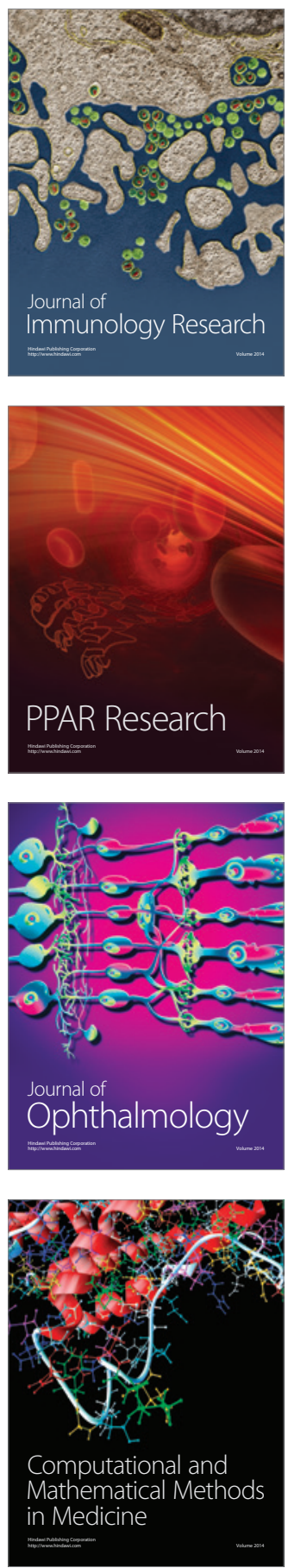

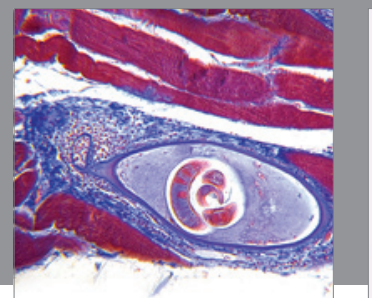

Gastroenterology

Research and Practice
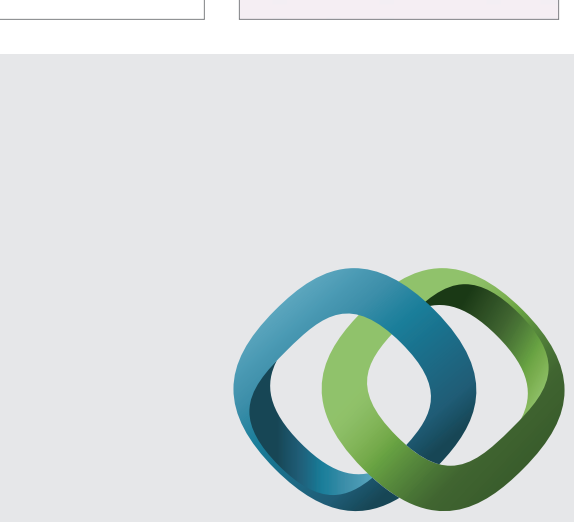

\section{Hindawi}

Submit your manuscripts at

http://www.hindawi.com
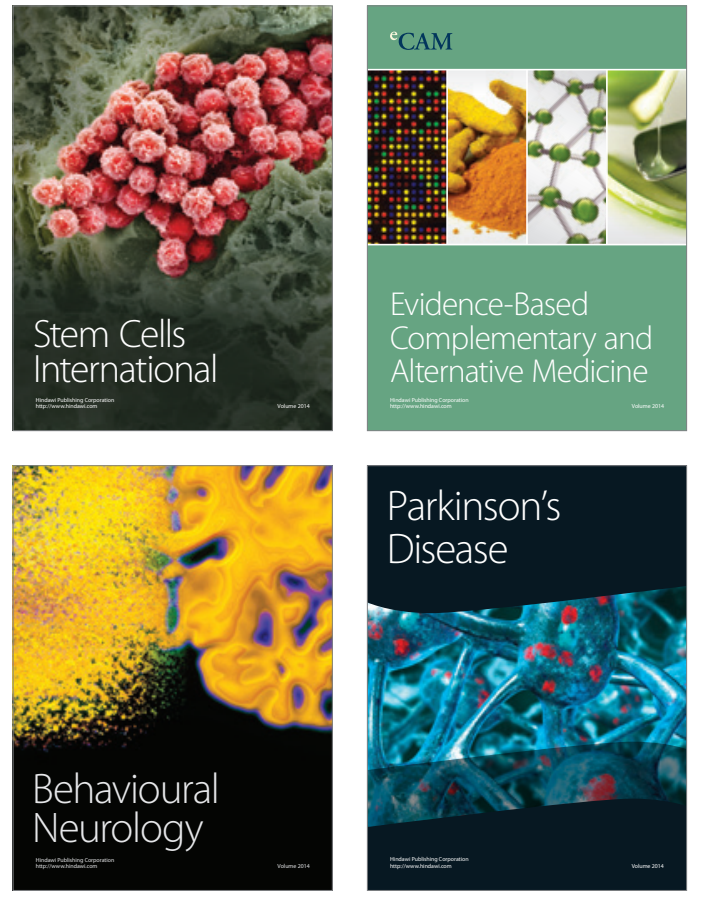
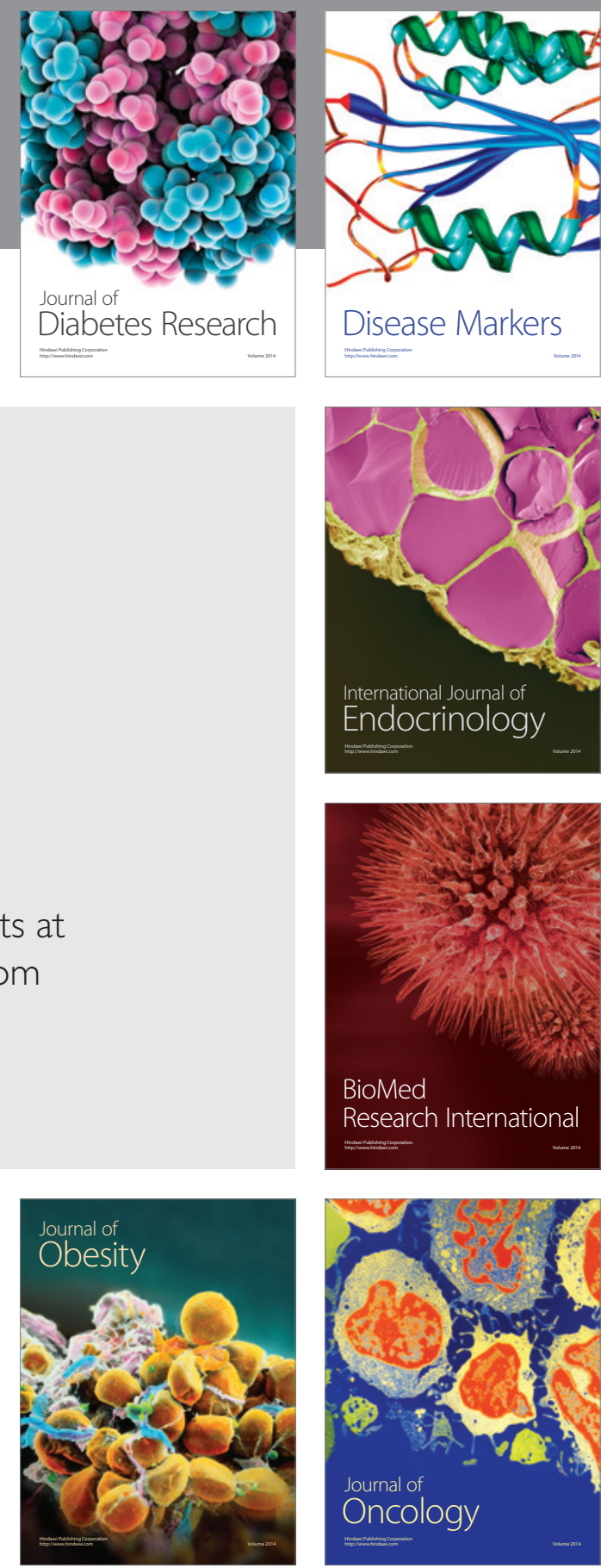

Disease Markers
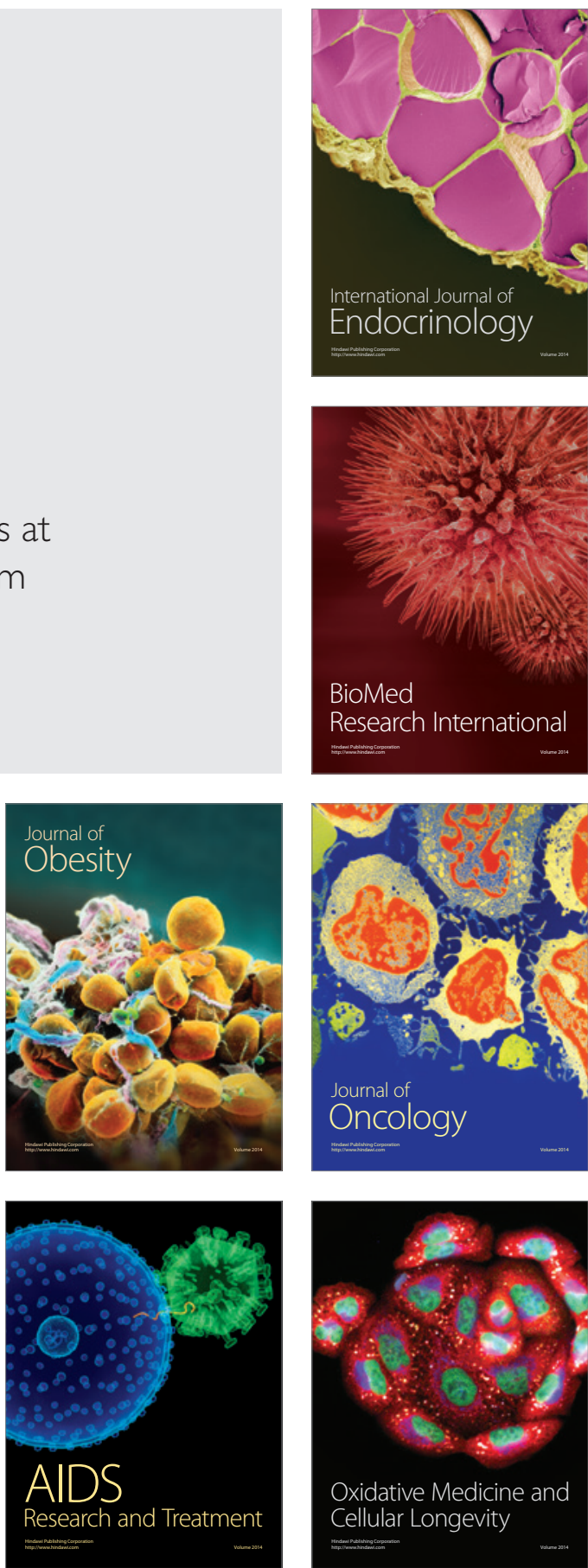